\title{
Loomad Rootsi-aegse Tartu ülikooli meditsiinitöödes
}

\author{
Kaarina Rein \\ Tartu Ülikooli raamatukogu teaduskeskuse teadur \\ kaarina.rein@ut.ee
}

\begin{abstract}
Teesid: Artikkel analüüsib loomade esinemist Rootsi-aegse Tartu ülikooli meditsiinitöödes. Vaatluse all on kolm Academia Gustaviana ning üks Academia Gustavo-Carolina aegne arstiteaduslik töö. Varauusaegse zooloogia arusaamade kohaselt oli inimesel täielik õigus kasutada loomi oma vajadusteks, sest looma peeti inimesest madalamaks olevuseks. Rootsi-aegse Tartu ülikooli arstiteaduslikes töödes mainitakse veterinaarmeditsiini, loomade kasutamist ravimite toorainena ja vihjatakse loomade lahkamisele teaduse huvides. 17. sajandi esimesel poolel koostatud meditsiinitööd toetuvad suuresti antiikautoritele ja Piiblile, kuid sajandi lõpus kirjutatud töö edastab tolleaegseid empiirilisi teadmisi. Loomadest räägitakse kõigis mainitud tekstides ka metafoorselt, võrdlemaks nende käitumist inimese omaga. Nii oli loomadel kindlasti teatav mõju arstiteaduse arengule Rootsi-aegses Tartu ülikoolis ning samuti sellele, kuidas tollal meditsiinist räägiti ja kirjutati.
\end{abstract}

Märksõnad: disputatsioonid, oratsioonid ja dissertatsioonid; loodusteadused varauusajal; teadus Rootsi-aegses Tartu ülikoolis; varauusaegne meditsiin

\section{Sissejuhatus}

Tartu ülikool rajati 1632. aastal Rootsi kuningriigi teise ülikoolina. Paljud tänapäeval tavalised teadussuunad alles hakkasid sel ajajärgul arenema. Nii on 17. sajandi Tartu ülikoolist teada vaid mõned meditsiinitööd ja üksainus botaanikaalane disputatsioon, kuid selliseid töid, mida võiks nimetada zooloogiaalasteks, ei olegi sealt meieni jõudnud. Loodusteaduslikke töid koostati varauusaegses ülikoolis peamiselt filosoofiateaduskonnas, kuid mis puudutab loomi, siis need on nii mõnigi kord leidnud käsitlemist ja mainimist Rootsiaegse Tartu ülikooli meditsiinialastes kirjutistes ja kõnedes. Tartu ülikooli esimene põhikiri sätestas, et tulevased arstid peavad looduslugu (philosophia naturalis't) õppima Johannes Magiruse õpiku "Physiologiae Peripateticae libri sex" (Peripateetilise füsioloogia kuus raamatut, esmatrükk 1597) järgi (Constitutiones 1997: 56-57). Selle teose V raamatus on 14. peatükk pühendatud loomade liikidele ja nende jaotusele vastavalt Aristotelese filosoofiale, ja seda koos Johannes Magiruse kommentaaridega (Magirus 1601: 540-560). 
Aristotelese teosest "Loomadest" lähtuvalt allus loodus perfektsuse astme järgi kindlale hierarhiale, elutust mateeriast kuni ülima hingestatuseni. Seda sai piltlikustada "olemise redelil" (scala naturae), mille alumistel astmetel asusid mineraalid ja taimed, neile järgnesid erinevad loomaliigid ja kõrgeimal astmel inimesed (Kalling 2017: 77). Keskajal paiknesid inimestest ülalpool inglid ning kõige kõrgemal troonis Jumal (Blackburn 2002: 324). Säärane "olemise redeli" mudel, mis demonstreeris elusolendite perfektsuse taset, oli loodusteadlaste hulgas populaarne umbes 19. sajandi keskpaigani (Kutschera 2011: 1).

Ka varauusaegsetes zooloogiat puudutavatest aruteludes olid kesksel kohal antiikajast pärit traditsioonid. Üks varauusaegse loomateaduse hämmastavaid jooni oli asjaolu, et teadmisi loomadest ammutati Aristotelese, Plinius Vanema, Athenaiose ning teiste antiikautorite tekstidest ka sel juhul, kui empiirilised teadmised olid käepärast (Enenkel \& Smith 2007: 7). Võrdlusena võib veel välja tuua, et botaanika ajalugu on uuritud tunduvalt rohkem kui zooloogia ajalugu (Enenkel \& Smith 2007: 3) ning Tartu ülikooli esimest botaanikaalast disputatsiooni (Stregnensis \& Andreas Arvidi 1647) on samuti mõnevõrra juba kajastatud (Piirimäe 1982: 239; Rein 2020: 24-26) ja seda tööd võib lugeda ka eesti keeles (Stregnensis \& Andreas Arvidi 2020: 4-23). Käesoleva artikli eesmärk on täiendada uurimusi Rootsi-aegse Tartu ülikooli arstiteaduse ja loodusfilosoofia kohta ning tuua välja loomade kujutamine ja mainimine Academia Gustaviana (1632-1656) ja Academia Gustavo-Carolina (1690-1710) meditsiinitöödes, nii disputatsioonides, dissertatsioonides kui ka oratsioonides.

Kaasaegse zooloogia alged rajasid Conrad Gessner ja tema mõttekaaslased juba 16. sajandil ning loomade ja loomaliikide ümberdefineerimine tõi kaasa zooloogia "leiutamise" (Enenkel \& Smith 2007: 1-3). Varauusaegseid lähenemisi loomadele on siiani uuritud vähe, sel sajandil avaldatud käsitlustest võib eelkõige välja tuua on Karl Enenkeli ja Paul Smithi mahukad artiklikogumikud, kus uuritakse loomade kasutamist erinevates valdkondades nii teoorias kui praktikas ning muuhulgas ka veterinaarmeditsiini (Enenkel \& Smith 2007 ja 2014). Kui keskenduda meditsiinivaldkonnale, siis suhteid loomade ja inimeste vahel arstiteaduses antiikajast kuni kaasajani on kujutatud eraldi artiklikogumikus, vt Hoffstadt \& Peschke \& Nagenborg \& Müller 2012. Loomade kasutamist haiguste ja vigastuste korral on täheldatud nii keskaegsetes bestiaariumites (White 2017: 222) kui ka eesti rahvameditsiinis (vt Sõukand 2006: 87-105; Kõivupuu 2017: 261-302). Võib oletada, et säärane praktika oli Eesti- ja Liivimaal kasutusel ka varauusajal.

Loomateadus varauusaegses akadeemilises kultuuris on üks teemasid Maija Kallineni monograafias Turu ülikooli loodusteaduslikest disputatsioonidest, kus on kirjeldatud vaala, tuvisid ja elevante, kuid autor nendib, et suurem osa infot võeti otse antiikautoritelt või 17. sajandi Aristotelese vaadete pooldajate 
tekstidest (Kallinen 1995: 228-230). Nagu juba ära toodud, 17. sajandi Tartu ülikoolist eraldi zooloogilisi teadustöid meieni jõudnud ei ole, kuid siinset artiklit võib pidada uurimuseks loodusteaduste ja meditsiini suhetest varauusajal. Seejuures on huvitav vaadelda, kas teadmised loomadest Rootsi-aegses Tartu ülikoolis olid empiirilised või põhinesid eelkõige antiikautoritel, nagu seda võis täheldada Turu ülikooli disputatsioonides.

\section{Loomad meditsiinis antiikajast varauusajani}

Varauusaegne zooloogia lähtub dogmast, et inimesel on täielik õigus kasutada loomi oma vajadusteks (Enenkel \& Smith 2007: 2). Euroopa meditsiinis on loomad antiikajast saati olnud ravimite allikaks. Seda tõendab seegi, et tänu madude ja nende mürgi kasutamisele Vana-Kreeka meditsiinis on maost saanud arstiteaduse sümbol (Leven 2005: 777). Varauusaegsel Prantsusmaal pidi iga ravim sisaldama vähemalt ühte komponenti loomariigivallast (Brockliss \& Jones 1997: 161). Madu võib mõistagi olla ka ohtlik ja siinkohal tasub meenutada tema osa Piibli pattulangemisloos (1 Mo 3:1-15).

Vanakreeka kirjanduses esinevad loomad erinevates rollides, kuid põhiliselt paistavad nad olevat metafoorid, mille abil väljendatakse võrdlusi nii teadus- kui ka ilukirjanduses (Korhonen \& Ruonakoski 2017: 42). Varauusaja kontekstis on mainitud, et loomad on kõige enam mõjutanud teoloogiat ja filoloogiat (Enenkel \& Smith 2014: 1), ent meditsiiniski leiab arvukalt väljendeid, milles sisaldub mõne looma nimetus, ja seda nii anatoomia- kui diagnostikaterminites. Siinkohal mõned näited: cochlea (tigu), cor bovinum (härjasüda), dens caninus (silmahammas), ${ }_{1}^{1}$ facies leontina (lõvinäosus), fames canina ehk lycorexia ehk bulimia (koeranälg, hundiisu, härjanälg), faux lupina (hundikurk), labium leporinum (jänesemokk), pes anserinus (hanejalg), pes equinus (hobupöid), vermis cerebelli (väikeajuuss) (Valdes \& Veski 1982-1983: passim). Seega on loomad andnud olulise panuse kirjeldamaks inimest ja tema seisundeid.

Esimene Euroopa kirjandusteos, kreeka eepos "Ilias" algab Apolloni saadetud katku kirjeldusega. See tõbi on kreeklaste sõjaväelaagrisse saadetud karistuseks preestri solvamise eest. Katku ohvritena on "Iliase" esimese laulu 50. värsireas kõigepealt mainitud muulasid ja koeri. Lisaks on loomad olnud nii antiik- kui ka varauusajal teaduskatsete ohvrid. Tuntuim Vana-Rooma arst Galenos (129- ca 200/ ca 216 AD) viis läbi lahkamisi nii elavate kui ka surnud imetajate peal, keskendudes sigadele ja primaatidele (Gerabek \& Haage \& Keil \& Wegner 2007: 450). Galenose põhihuvi oli inimese anatoomia, kuid Rooma õigus keelas inimlaipade lahkamist. Sellegipoolest uskus Galenos, et lahatud loomade anatoomiline ülesehitus annab hea ülevaate inimese ülesehitusest 
ning Galenose tehtud järeldused mõjutasid ettekujutust inimanatoomiast ja -füsioloogiast kuni 16. sajandini, sest inimesi peeti loomade analoogideks (Garrison 1960: 113-114). Varauusajal kasutati loomakehi koguni selleks, et mõista inimloomuse sügavusi (Muratori 2017: 2). René Descartes’i (1596-1650) teooriat loomadest kui masinatest kritiseerisid teravalt paljud tema kaasaegsed, kuid sellegipoolest andsid need teadlastele võimaluse õigustada seda, mida tänapäeval kutsutakse võigasteks katseteks ajal, mil anesteesia polnud kättesaadav ei inimestele ega loomadele (Franco 2013: 241).

Arstiteaduses ei ole loomad siiski ainult tooraineallikad, katseloomad ja ohvrid, vaid astuvad üles ka kliendi rollis. Meditsiiniharu on ka veterinaarmeditsiin ning loomahaigused ja nende ravi peegelduvad juba antiikkirjanduses, siinkohal võib mainida autoreid nagu Aristoteles, Cato, Varro, Columella jne. Loomaarstiteaduse põhihuvi oli suunatud hobustele ja veistele, st majanduslikult olulistele loomadele (Achner 2009: 146-152). Üks esimesi säilinud tekstikogumeid veterinaarmeditsiinist oli "Mulomedicina Chironis" ( $c a 400$ A.D.), mis demonstreerib, et antiikne loomaarstiteadus ei jäänud inimmeditsiinist maha ei diagnostika, etioloogia ega terapeutika vallas (Leven 2005: 864). Mis puudutab varauusaega, siis 16 . ja 17 . sajandil veterinaarmeditsiini ametlikult ei eksisteerinudki, vaid loomad olid väidetavalt posijate ja kohalike ravitsejate meelevallas, sagedamini ravis neid külasepp (Brockliss \& Jones 1997: 455-456).

Ülaltoodud näited osutavad, et loomade seos meditsiiniga oli mitmekesine ja võib eeldada, et sarnased suhted on täheldatavad ka varauusaegsetes Tartus koostatud akadeemilistes tekstides.

\section{Loomad Academia Gustaviana meditsiinitekstides}

Rootsi-aegse Tartu ülikooli esimesest tegevusperioodist ehk Academia Gustaviana ajast on meieni jõudnud kolm teksti - kaks oratsiooni ja üks disputatsioon -, mis mainivad või kirjeldavad mingil kujul loomi: 1) "Oratio de medicina" (Kõne meditsiinist) Friedrich Heini ettekandes (1637, 24 lk); 2) "Oratio de homine" (Kõne inimesest) Sequardus Wallanderilt (1640, $20 \mathrm{lk}$ ) ja 3) "Disputatio medica de natura et constitutione medicinae" (Arstiteaduslik disputatsioon meditsiini olemusest ja ülesehitusest) Andreas Arvidi sulest Sebastian Wirdigi eesistumisel (1648, $28 \mathrm{lk}){ }^{2}$ 


\subsection{Oratio de medicina}

Friedrich Hein, "Oratio de medicina” eeldatav autor, väidab, et meie, inimesed, peame loomade eest hoolitsema, sest loomad on loodud inimestele kasutamiseks ning seega hindavad paljud veterinaarmeditsiini. Kõnes tuuakse välja rida antiikautoreid, kes on kirjutanud loomade haigustest. Nii kirjeldab Vergilius oma õpetlikus põllutööpoeemis "Georgica” hobuseid ja mesilasi, Columella kirjutab lammaste ning Varro kitsede haigustest (Hein 1637: A4 v). ${ }^{3}$ Tuntuimate kreeka keeles kirjutanud antiikteadlaste nagu Aristotelese või Galenose loomingut oratsioonis ei mainita.

Järgmiseks kutsub oratsiooni autor oma publikut tunnistajaks Tartus läbi viidud lahkamistele (Hein 1637: B). ${ }^{4}$ Kõnealused lahkamised, kui need tõesti toimusid, olid päris kindlasti loomade ja mitte inimeste peal läbi viidud. Inimlaipade lahkamisi ei ole Tartus sellest ajast teada, kuigi põhikiri seda arstiõppes ette nägi (Constitutiones 1997: 56-57). Sedasorti sündmused oleksid kindlasti ülikooli ajalugu puudutavates allikates kajastunud. „Oratio de medicina“ näib viitavat, et loomade lahkamisi tuli siiski ette.

Autor toob näite ka Vana Testamendi Tobiase raamatust (6:5), kus peaingel Raafael ütles Tobiasele, et too hoiaks alles kala südame, sapi ja maksa, et kasutada neid kui ravimeid, eriti kala maks olevat kasulik kui silmarohi (Hein 1637: B3 v). ${ }^{5}$ Teisalt mainib oratsiooni autor, et kala võib tervisele olla nii kasulik kui kahjulik (Hein 1637: C v).

"Oratio de medicina” mainib ära ka vanakreeka müüdi, mille kohaselt Theseuse poja Hippolytose rebisid õnnetul kombel tükkideks tema enda lõhkuma hakanud hobused ja arstimisjumal Asklepios äratas noormehe uuesti ellu (Hein 1637: B4). ${ }^{6}$

Tõenäoliselt kõige huvitavamad osad sellest meditsiinialasest kõnest on lõigud, kus loomadest kõneldakse kui omaenda tohtritest. Oratsiooni autor rõhutab, et targad arstid peaksid loomadelt õppima. Näidete hulgas tuuakse välja toit ja taimed, mida loomad teatud juhtudel kasutavad, kas siis mürkide vastu või oma tervise, nt nägemise parendamiseks. Nii väidetakse kõnes, et Egiptuse lind iibis oskavat enese ravimisel kasutada oksendusvahendeid, hirv kasutavat Kreeta punet, et hõlbustada noolte eemaldamist, metssiga aga luuderohtu, et ravida mürgiseid hammustusi, kilpkonn kasutab punet madude vastu ja nirk ruutu mürgi vastu (Hein 1637: B4 v). ${ }^{7}$ Loetelu loomade tarkusest jätkub veelgi, kuid need teadmised ei pärine autorilt endalt, vaid loomade seos teatud taimedega on võetud vanarooma entsüklopedisti Plinius Vanema "Loodusloost". ${ }^{8}$ Seega pole ka mainitud loomad ilmtingimata need, keda võis kohata Euroopa põhja- või idapoolsetes regioonides ja kellega kõne autor võis kokku puutuda. Nii võib siingi näha toetumist loetud antiikautoritele. 
1637. aastal Tartus koostatud "Oratio de medicina" annab loomadest rõhutatult positiivse pildi, kuigi vihjatud on ka Hippolytosele, kes omaenda hobuste tõttu hukkus. Autor väidab varauusajale iseloomulikult, et loomad on loodud inimese tarbeks. Seetõttu toob ta välja ka veterinaarmeditsiini tähtsuse ja loomade eest hoolitsemise. Empiirilisi teadmisi võib kõnes täheldada vihjetest lahkamistele. Muus osas on antiikautorid ja Vana Testament põhiallikad loomade, nendega seotud ravimite, haiguste ravi ja veterinaarmeditsiini kohta. Friedrich Hein rõhutab oma kõnes Plinius Vanema tekstile toetudes, et inimesel on meditsiini vallas loomadelt palju õppida (Hein 1637: B4 v-C).

\subsection{Oratio de homine}

Sequardus Wallander kandis "Oratio de homine" Tartu ülikoolis ette aastal 1640, seega kolm aastat pärast eelmist meditsiiniteemalist kõnet. Võib täheldada, et selles oratsioonis on loomi mainitud vaid metafooridena ja "olemise redeli" mudelist lähtuvalt alamat sorti olevustena. Juba kõne sissejuhatuses rõhutatakse, et kui inimene ei käitu korralikult, kuulub ta pigem loomade sekka, kuna inimeste elu jääb inglite ja kariloomade elu vahepeale (Wallander 1640: A2). ${ }^{9}$ Tuuakse ka näide kuningas Nebukadnetsarist Vana Testamendi Taanieli raamatus (4:30), kes sõi heina kui härg ja kelle juuksed muutusid kotkasulgede sarnaseks ning küüned linnuküünisteks (Wallander 1640: A3 v). ${ }^{10}$

Demonstreerimaks loomade halbu külgi on oratsioonis kasutatud veel väljendeid beluina voluptas (loomalik nauding) ja Est Homo Homini soepius Lupus (inimene on inimesele sagedamini hunt) (Wallander 1640: C-C2). Viimase väljendi leiab Plautuse komöödiast"11 ning "Oratio de homine" lõpus on tsitaat Ovidiuselt, mis rõhutab inimese üleolekut loomadest. ${ }^{12}$

Kui arvata välja tsitaadid Plautuselt ja Ovidiuselt, on Sequardus Wallanderi kõnes põhiline loomade kohta käivate näidete allikas Vana Testament. Kogemuslikku kokkupuudet loomadega ei ole "Oratio de homine" tekstis mainitud.

\subsection{Disputatio medica de natura et constitutione medicinae}

Rootsi-aegse Tartu ülikooli kolmanda loomadele viiteid sisaldava meditsiinitöö "Disputatio medica de natura et constitutione medicinae" üle väitles 1648. aastal meditsiiniprofessor Sebastian Wirdigi eesistumisel üliõpilane Andreas Arvidi, keda on töö tiitellehel nimetatud ka töö autoriks, vt Rein 2008: 16 ja 2011: $123,136$. 
Disputatsiooni esimene osa on pühendatud meditsiini defineerimisele, ning rääkides homonüümiast ütleb autor, et see on segaduste tekitaja ja seega peab sõna "meditsiin" kasutamisel olema ettevaatlik. Nimelt laiemas tähenduses kuulub selle distsipliini alla ka veterinaarmeditsiin (Wirdig-Andreas Arvidi: A3 v). ${ }^{13}$ Seega eristati 17. sajandi Tartu ülikoolis inim- ja veterinaarmeditsiini. Viimane oli selgelt madalamat sorti ala kui inimestele pühendunud arstimise kunst.

Teine koht, kus loomi Andreas Arvidi disputatsioonis mainitakse, on lõigus, kus selgitatakse, kes on üldse võimeline arstiteadust tudeerima. Sealkohal tsiteeritakse Hippokratese traktaati "Seadus", kus öeldakse, et kui keegi, kel pole meditsiini õppimiseks loomupärast annet, püüab seda kunsti omandada, on see sama hea kui ühendada hunte lammastega või madu pärdikuga (Hippokrates 1981: 262-263). ${ }^{14}$

Seega pole mainitud disputatsioonis loomadest juttu just palju, loomad on eelkõige metafoorid, vihjatakse ka nende hooldamisele ehk veterinaarmeditsiinile.

\subsection{Kokkuvõte Academia Gustaviana meditsiinitekstide kohta}

Kokkuvõtteks võib öelda, et kolmes Academia Gustaviana meditsiinitöös käsitletakse teemasid veterinaarmeditsiin, loomade lahkamine, loomad ravimite toorainena, loomade tehtud või tehtav kahju ning loomad iseendi ravitsejatena. Samuti kasutatakse loomi võrdlustes sageli metafooridena. Loomade puhul on analüüsitud oratsioonides täheldatav, et mitmeid näiteid on toodud Vanast Testamendist, kuid mitte ainsatki Uuest Testamendist. Järeldada võib, et Vanas Testamendis on rohkem juttu loomadest meditsiini kontekstis, samas kui Uues Testamendis on inimeste osakaal olulisem. Kõned kandsid ette teoloogiatudengid, seega pole näited Piiblist üllatavad. Palju on vihjeid ka Kreeka ja Rooma autoritele, kuid isiklikku kokkupuudet loomadega pole Academia Gustaviana meditsiinitöödes peaaegu üldse kajastatud.

\section{Loomad Academia Gustavo-Carolina meditsiinitekstides}

Rootsi-aegse Tartu ülikooli kolm esimest loomi käsitlenud või maininud meditsiinitööd olid ajaliselt üksteisele suhteliselt lähedal, kattes ajavahemiku 1637-1648. Kuna ülikoolis 17. sajandi teisel poolel õppetöö seiskus, koostati neljas sellesarnane töö hoopis hiljem, aastal 1698 Academia Gustavo-Carolina 
perioodil. ${ }^{15}$ Selle arstiteadusliku dissertatsiooni eesistuja oli meditsiiniprofessor Jacob Friedrich Below (1669-1716) ning töö kandis ette teoloogiatudeng Salomon Matthiae. Töö sissejuhatuses on mõista antud, et dissertatsiooni autor on Jacob Friedrich Below, kuid selle lõppu lisatud teesid on Salomon Matthiae sulest. Meditsiiniprofessor Belowiga seotud teadustöödes võis hiljemgi kohata loomade temaatikat (vt Recke \& Napiersky 1831: 100).

\subsection{Jacob Friedrich Belowi ja Salomon Matthiae meditsiinidissertatsioon}

Jacob Friedrich Belowi ja Salomon Matthiae dissertatsiooni pealkiri oli "Circuli anatomico-physiologici minoris, segmentum primum; seu dissertatio prima de oeconomia corporis animalis, cogitata, functionum animalium potissimarum Formalitatem \& causas concernantia" (Väiksema anatoomia-füsioloogia ringi esimene segment ehk esimene dissertatsioon elusolendite keha korraldatusest kavatsusega puudutada elusolendite tugevaimate funktsioonide seaduspära ja põhjuseid, 36 lk). Kuigi töö pealkirjas sisalduv sõna "animal” tähendab laiemalt hingega olendit või elusolendit, võib seda mõista ka loomana. On ka näha, et pealkirjas sisaldub sõna “esimene”, mistõttu võib arvata, et teemale oodati järge.

Antiikajast varauusajani oli tavaline, et loomalaipade lahkamise tulemuste põhjal tehti järeldusi inimanatoomia kohta (Wright 2013: 30-39), toetudes antiikaegse kuulsaima arsti Galenose kirjeldustele (vt käesoleva artikli 2. ptk). Seevastu töös "Dissertatio prima de oeconomia corporis animalis" tundub olevat vastupidi. Nimelt väidab dissertatsiooni autor oma töö sissejuhatuses, et ta sai oma kirjutise jaoks inspiratsiooni inimlaiba lahkamisest, mis leidis hiljuti aset Tartu ülikoolis, ning autori eesmärk on lahkamistega jätkata, et rahuldada avalikku uudishimu. Sellegipoolest mainib autor, et lahkamine ei pruugi olla kõigile meeldiv vaatepilt (Below-Salomon Matthiae 1698: A1).

Ning tõesti, kui Jacob Friedrich Belowist sai 1695. aastal Tartu ülikooli meditsiiniprofessor, pidas ta oluliseks illustreerida oma loenguid lahkamistega ja 1697/98. õppeaasta talvel anatomeeris Below kaks inimlaipa (Rauch 1943: 276). See oli ajalooline sündmus, kuna arvatavalt leidis selline asi Tartu ülikoolis aset esmakordselt.

1698. aasta 28. mail kanti Tartu ülikoolis ette mainitud dissertatsioon elusolendi keha toimemehhanismidest, kus autor väitis, et sel tööl on otsene seos eelnevate inimlaipade lahkamisega (Below-Salomon Matthiae 1698: A1). Selle väitekirja teema on üldisemalt seedefüsioloogia. Selgitus dissertatsiooni pealkirjale on esitatud sissejuhatuses - töö väidetakse põhinevat 1697. aastal Leipzigis trükitud Johannes Bohni (1640-1718) tööl, millel oli sarnane pealkiri. ${ }^{16}$ 
Johannes Bohn oli Leipzigi ülikooli meditsiiniprofessor, keda mõjutasid kartesiaanlikud ideed ning tema mõju Saksamaal ja samuti Skandinaavias oli märkimisväärne (Tering 1996: 187). Tema raamat "Circulus anatomicophysiologicus" oli pühendatud tema sõbrale, kapillaaride avastajale Marcello Malpighile (1628-1694), vt Bohn 1697: a2. Johannes Bohni monograafia hõlmab 500 lehekülge ja sisaldab 30 peatükki, kus teemad algavad sigitamise ja eostamisega ning annavad ülevaate füsioloogiaga seonduvast - hingamisest, vereringest, seedimisest, erinevate siseorganite funktsioneerimisest, meeltest jne. Viimane peatükk jutustab une tähtsusest (Bohn 1697: 1-478).

Tartus koostatud Jacob Friedrich Belowi ja Salomon Matthiae dissertatsioon ei ole sama laia haardega nagu Johannes Bohni monograafia, vaid keskendub seedefüsioloogiale, kajastades seega kõigest väikest osa Johannes Bohni raamatu teemadest. Ent autorite eesmärk dissertatsiooni koostamisel, mis on mainitud töö sissejuhatuses, on ambitsioonikas - nimelt korrigeerida vastukäivusi Johannes Bohni käsitluses, kuid teha seda diskreetselt ilma autori vigadele osutamata.

\subsection{Seedimise kujutamine Jacob Friedrich Belowi ja Salomon}

\section{Matthiae dissertatsioonis}

Teemade osalisele sarnasusele vaatamata paistab, et Johannes Bohni monograafias ning Jacob Friedrich Belowi ja Salomon Matthiae dissertatsioonis on ladinakeelset sõna animal tõlgendatud erinevalt. Johannes Bohni jaoks tähendab see laiemalt elusolendit, kellel on hing (anima), sellal kui Tartus esitatud dissertatsioonis on märksa rohkem viiteid konkreetselt loomadele.

Samuti on Johannes Bohni raamatus eraldi peatükk pühendatud imetajate vereringe kirjeldusele, mille avastas William Harvey 1628. aastal (Bohn 1697: 97-114). Ka Jacob Friedrich Belowi ja Salomon Matthiae dissertatsioon mainib vereringet kui 17. sajandi olulist avastust ning kirjeldab esimeses peatükis protsessi, kuidas veri kehas toitu laiali kannab (Below-Salomon Matthiae: A2-A3).

Edasi selgitatakse Tartus koostatud töö teises peatükis näljatunde teket, mida põhjustavat vähem happeline ja mõõdukalt soolane lümf, mida eritab veri ja mis voolab kokku tühja makku (Below-Salomon Matthiae: A3). Janu aga tekitavat vedelikupuudus, mis vaevab magu ja tõuseb mõnikord kurguni (Below-Salomon Matthiae: A3 v).

Kolmandas peatükis on juttu toidu purustamisest ning hammaste, keele ja sülje funktsioonidest sealjuures. Neelamistegevus algab keelest, seega on keele haigused ja vigastused siinkohal takistuseks, samuti olla täheldatud, et 
neelamise teeb raskemaks ülearu pikk keel, nagu on konnadel (Below-Salomon Matthiae: B2 v).

Neljas peatükk keskendub küüluse ehk piimandi tekkele, kus loomade seedeprotsessi on kirjeldatud rohkete detailidega. Autor ütleb, et loomade maos on alati vedelikku, mis on lihtne ja puhas nende loomade puhul, kes söövad pikemate vahede tagant, ning paks ja ebaühtlane nende lojuste puhul, kes söövad iga päev ning sageli (Below-Salomon Matthiae: B4). ${ }^{17}$ Mõõdukat toiduhulka tarbitakse kiiremini kui suuremat, keedetut kiiremini kui toorest, korralikult läbinäritud toit toodab küülust paremini kui tervelt allaneelatu. Piimanditekke aeg varieerub ka vastavalt sööjate erinevusele, see on kas spetsiifiline või individuaalne. Esimesel põhjusel seedivad hunt ja koer toitu enamasti kiiremini kui inimene (Below-Salomon Matthiae: C). ${ }^{18}$ Neljandas peatükis on juttu ka sapist ja kõhunäärme mahlast ning sellest, et kõhunäärme kanal asetseb inimesel, kassil, karpkalal, angerjal lähestikku sapijuhaga, see iseloomustavat kõiki elusolendeid, kel on sapijuha olemas (Below-Salomon Matthiae: C2 v). Viies ja viimane peatükk räägib küüluse puhastamisest ja läbi soolte liikumisest, mille käigus tuleb see roojast eraldada. Siin võib näha metafoorset võrdlust loomadega, kus autor võrdleb soolte liikumist usside omaga ning selgitab, et üks osa sooltest sirutub välja justkui roomaks see läbi teokarbi (Below-Salomon Matthiae: C3-C4). ${ }^{19}$

Võrdlusena võib välja tuua, et eeskujuks olnud Johannes Bohni raamatus on mitmeid peatükke, mil on seos seedimisega ja mis kõnelevad nt toitumisest, isust, külifikatsioonist (piimanditekkest) ja eritamisest (Bohn 1697: 114-205). Loomi on Bohni monograafias harva mainitud, üks väheseid näiteid on inimese hammaste võrdlus kala, jänese, orava, hiire, koera, veise ja hobuse hammastega (Bohn 1697: 131). Mõlema töö autorid on ühel meelel selles, et toitumine on seotud hingevaimu(de)ga (ld spiritus animalis, kr pneuma psychikon) (Bohn 1697: 123; Below-Salomon Matthiae: A2 v). Hingevaimud asusid närvides ja need usuti olevat aju tekitatud (Leven 2005: 717-718).

Tartus koostatud töö "Dissertatio prima de oeconomia corporis animalis" lõpus on 36 teesi, millest viimastes (XXXIII, XXXIV, XXXVI) on samuti loomi mainitud. Suurem osa teesidest kajastavad René Descartes'i ja tema kriitiku Pierre Daniel Huet' (1630-1721) vaidlusi. Väitleja toetab Descartes’i seisukohta, et kõiges on vaja kahelda ja esitab selle seisukoha võimalikud väärtõlgendused (Below-Salomon Matthiae: D1 v-D3), samuti on teesides juttu hingevaimudest ja sellest, kuidas nad keha liikumist mõjutavad (Below-Salomon Matthiae: D3D4). Loomade kohta esitatud väited puudutavad eelkõige nende kehavedelikke ja viimaste kasutamist farmaatsias. Nii on seal kirjeldus kopra füsioloogiast ning selgitus tema eritatud kopranõre päritolust, mida kasutati rahvameditsiinis juba antiikajal ravimaks mitmesuguseid tõbesid. Dissertatsioonis selle 
nähtuse kohta toodud selgitus annab teada, et see eritis ei tule isase kopra suguelunditest nagu seni arvatud, vaid erilisest näärmest, mis on olemas nii isastel kui ka emastel isenditel ja mis on kanamuna suurune ning eritab õlist vängelt lõhnavat vedelikku, mida kobras lakub (Below-Salomon Matthiae: D4 v). ${ }^{20}$ See idee väidetakse pärinevat Thomas Bartholinilt (1616-1680), kes avaldas lümfisüsteemi kirjelduse aastal 1652. Johannes Bohni monograafias mainitakse Thomas Bartholini lisaks ka kui süljejuha avastajat (Bohn 1697: 135).

"Dissertatio prima de oeconomia corporis animalis" autor selgitab teesides ka spermatseedi ehk vaalavõidise päritolu. Nii väidetakse seal, et spermatseet ei ole sperma, vaid vedelik, mis tekib vaala ajus, kelle liiginimeks annab väitleja ladina keeles orca (mõõkvaal) (Below-Salomon Matthiae: D4 v). ${ }^{21}$ Kommentaarina võib lisada, et siinkohal ta eksib, sest see vahajas aine moodustub hoopis kašelottide ehk spermatseedivaalade peas (Physeter macrocephalus) ja mitte mõõkvaalade omas.

"Dissertatio prima de oeconomia corporis animalis" viimane tees pole kirjutatud ladina keeles, nagu 17. sajandil veel tavaks oli, vaid saksa keeles. Seal on öeldud, et suurim erinevus inimese ja rumalate kariloomade vahel on ratsionaalne hing, mis on olemas inimesel ja mida loomadel pole, mis seab inimesele kohustuse oma mõistmise kohaselt tegelda kaunite kunstidega, et olla korralik inimene. Ent neid, kes õpingute vastu põlgust tunnevad, ei saa pidada ratsionaalseteks inimesteks, mis tähendab, et nad on koletised (Below-Salomon Matthiae: D4 v). ${ }^{22}$ Seega võib siin sarnaselt Academia Gustaviana päevil peetud kõnega "De homine" näha hoiatust mitte laskuda looma kui madalamat sorti olendi tasemele.

Lisaks juba nimetatud autoritele (Johannes Bohn, René Descartes jt) on Jacob Friedrich Belowi ja Salomon Matthiae dissertatsioonis mainitud ka antiikautorite seisukohti, kuid toetutud on eelkõige varauusaegsetele õpetlastele (nt Caspar Bartholin noorem, Nicolaus Steno, Thomas Wharton, Anton Nuck, Gabriele Fallopio, Girolamo Fabrizi d'Aquapendente, Andreas Vesalius, Jean Riolan noorem, Jan Baptist van Helmont) ja ka isiklikele empiirilistele teadmistele.

\section{Kokkuvõte}

Rootsi-aegsest Tartu ülikoolist on teada neli meditsiinitööd, kus loomi on kas kirjeldatud või mingis seoses mainitud. Nendes kirjutistes kasutati loomi tihti kui metafoore, et tõmmata paralleele inimeste elu ja käitumisega, nagu oli tüüpiline ka antiikajale. Loomi peeti inimestest alamateks, nagu näeb ette 
“olemise redeli" mudel, ja tollaste arusaamade järgi olid loomad inimestele kasutamiseks.

Selget vahet võib näha meditsiinitööde, mis on koostatud 17. sajandi esimesel poolel, ja dissertatsiooni vahel, mis on kirjutatud 17. sajandi lõpus. Varem koostatud tööd toetuvad suuresti antiikautoritele ja Piiblile, samas kui 17. sajandi lõpu töö annab edasi varauusaegseid empiirilisi teadmisi. Võib näha, et Rootsi-aegse Tartu ülikooli arstiteaduslikes töödes mainitakse veterinaarmeditsiini, samuti loomade kasutamist ravimite toorainena ning isegi loomi iseenda ravitsejatena, kes õpetavad inimestele, kuidas teatud haigustest jagu saada. Vihjeid on ka loomadele teaduskatsetes.

Rootsi-aegse Tartu ülikooli meditsiinitöödest pole näha, kui palju puutusid nende tekstide autorid ise kokku loomadega, keda nad kirjeldasid, kuna nende kirjatööd põhinesid suuresti eelnevatel autoritel antiikajast kuni varauusajani. Siiski on tõenäoline, et nad olid näinud lahkamisi ja omasid kogemusi loomade kasutamisest apteekides. Töös "Dissertatio prima de oeconomia corporis animalis" aastast 1698 võib jälgida varauusaegse füsioloogia arengut.

Niisiis oli loomadel teatud mõju arstiteadusele Rootsi-aegses Tartu ülikoolis ning samuti viisile, kuidas Tartus meditsiinist räägiti ja kirjutati.

\section{Tänusõnad}

Artikkel on valminud Rootsi Teadusagentuuri grandi nr 2016-01881 "HellenoNordica: humanistide kreeka keel Rootsi suurriigis" ning teadus- ja arendusprojekti PHVFI1992 "Balti regiooni arstide varauusaegsete väitekirjade baasstandardi väljatöötamine” raames. Selle kirjutamine sai võimalikuks tänu Wolfenbütteli Hertsog Augusti raamatukogu stipendiumile aastal 2019. Artikkel ilmub ingliskeelsena ("Depiction of animals in the medical works of the 17 th century University of Tartu") kogumikus "Entangled Human-Animal Histories: Practices and Imaginaries from the Eastern Baltic Borderlands" (toimetajad Linda Kaljundi, Anu Mänd, Ulrike Plath, Kadri Tüür). Kirjastaja Peter Lang (Studies in Literature, Culture, and the Environment). Autor tänab artikli anonüümseid retsensente parandus- ja täiendusettepanekute eest.

\section{Kommentaarid}

1 Ladina keeles "koerahammas" ehk kaniin.

2 Saamaks ülevaadet Academia Gustaviana aegsetest meditsiinitekstidest vt Rein 2011, 2013 ja 2014, tollaste meditsiiniteemaliste oratsioonide kohta vt Rein 2017 ja 2019 ja Andreas Arvidi arstiteadusliku disputatsiooni kohta Rein 2008. 
${ }^{3}$ In vita communi receptum est, ut Medicinam brutorum animalium magnifaciant multi. ... Etenim, cum in usum hominum Bruta animantia sint creata; quando male habere inceperunt, cura indigent \& sollicitudine. ... Sic de Equorum morbis, agit Virgil. 3 Georg., De ovium cura, Columella lib. 8. De Caprarum medela, Varro de re Rustica lib. 2. c. 2. De cura apum \& morbis, Virg. 4. Georg.

${ }^{4}$ Etenim, versamur in sancto hoc Auditorio Academico-Medico, in quo publice Docentes identidem audimus Medicos ingeniosissimos. Vos Auditores inclyti, testes estis Anatomicae sectionis in corporibus soepius institutae ... .

5 Sic Raphael Angelus monuit Tobiam, ut capti piscis cor, fel \& jecur reponeret: ea enim esse necessaria ad medicamenta utiliter, praesertim fel valere ad oculos sanandos.

6 Postea, praenominatus ille Apollo excelluit, \& ejus filius Aesculapius, qui hujus Artis peritus, Dianae precibus, Hippolytum ab equis discerptum vitae restituit.

7 Etenim, monstravit Ibis, Aegyptica avis, vomendi modum. Cervus, dictamnum pro extrahendis sagittis; ... ut \& apri ijsdem contra ederam esam utuntur: ... testudo cunilae contra serpentis usum: mustela, contra venenum rutam ... .

8 Plinius Vanem „Looduslugu“, VIII rmt, 41. ptk.

9 Vita Hominum media inter Vitam \& Angelorum, \& Vitam pecorum. Si vixerit Homo secundum carnem \& ad delictorum illecebras feretur, pecoribus conjungetur.

${ }^{10}$ Erat \& Rex superbissimus Nabuchdonosor, qui abjectus, foenum ut bos comedit, \& rore coeli corpus ejus infectum est, donec capilli ejus in similitudinem aquilarum crescerent, \& ungues ejus quasi ungues avium.

11 Plautus “Asinaria” (Eeslikomöödia), 495.

12 Ovidius "Metamorfoosid", I rmt, värsid 76-88.

${ }^{13}$ Circa Homonomiam, quae Errorum genetrix a Philosophis salutari solet, tenendum est, Vocabulum Medicinae accipi hoc loco, non Improprie \& Abusive. Sic enim obtinet Significationem I. Latiorem, \& ambitu suo, veterinariam \& Mulomedicinam includit.

${ }^{14}$ Causa Efficiens Secunda Medicinae addiscendae est I. Naturalis aptitudo; quippe ut ait Medicorum ille Coryphaeus Hippocrates Lib. de Lege, Natura reluctante irrita sunt omnia; \& vere, qui enim natura ineptus natus ad Medicinam, artem illam nihilominus addiscere tentat, is aut lupos agnis, aut serpentem simiae conciliare ... (Wirdig-Andreas Arvidi: B3 v-B4).

${ }^{15}$ Saamaks ülevaadet Academia Gustavo-Carolina aegsetest meditsiinitöödest vt Rauch 1943: 279-286 ja Piirimäe 1982: 232-238.

${ }^{16}$ Bohn, Johannes: "Circulus anatomico-physiologicus seu oeconomia corporis animalis, hoc est, cogitata, functionum animalium potissimarum formalitatem et causas concernantia" (Anatoomilis-füsioloogiline ring ehk elusolendi keha korraldatus, mis puudutab elusolendite tugevaimate funktsioonide seaduspära ja põhjuseid). Lipsiae, Apud Thomam Fritsch, 1697. Selle teose varasem väljaanne trükiti aastal 1686.

${ }^{17}$ Reperitur nempe semper in quorumcunque animalium ventriculis fluidum quoddam simplex \& sincerum magis in illis, quae aliquam mediam passasunt, turbidum vero crassius \& heterogeneum magis, si victu quotidiano ac frequenti fruatur animal.

${ }^{18}$ Ratione prioris, lupus \& canis citius ut plurimum digerunt quam homo.

${ }^{19}$ Hic intestinorum motus ... vulgo peristalticus lumbricalis atque vermicularis dicitur, quod pariter ac vermis flexuosis gyris per totam sui longitudinem modo constringantur, modo dilatentur intestina, \& horum una pars quasi per cochleam explicetur, proxima constricta, nunc subsideat haec, attollatur altera. 
${ }^{20}$ XXXIII. Castorei testiculi magnitudine vix superant gallorum gallinaceorum testes, falsum igitur est, illud medicamen quod in pharmacopoliis castorei nomine venditur, hujus animalis esse testiculos. Sed, sunt tantum binae glandulae quae tam in maribus quam in foeminis horum animalium reperiuntur: \& quidem utrinque in inguinibus, statim sub cute, ovorum gallinaceorum magnitudine \& saepe majores conspiciuntur, ex quibus liquor oleosus \& gravi odore emanat, quem animal lingua lambit. Bartholin.

${ }^{21}$ XXXIV. Sperma ceti non est sperma, sed liquor arte paratus, saepe maris summitati innatans, ex cerebro, non cujusvis ceti, sed hujus generis qui orca vocatur, oriundus.

${ }^{22}$ XXXVI. Weil der grösseste Unterscheid/ so zwischen einem Menschen und einem tummen Viehe ist / darin bestehet / daß der Mensch eine Vernünftige Seele hat / das Vieh aber nicht: so wird ein jeder gestehen müssen / daß nur die jenige/ so ihren Verstand durch schöne Wissenschafften excoliren, für rechte Menschen zu halten: alle andere aber / so die Studien verachten/ und ihr Gespött damit treiben/ für unvernünftige Menschen / das ist für Unmenschen zu achten sind.

\section{Allikad}

Andreas Arvidi \& Stregnensis, Johannes 2020. Loodusteaduslik disputatsioon taimedest. Vikerkaar 7-8, lk 4-23.

Below, Jacob Friedrich \& Salomon Matthiae 1698. I. N. J. Circuli anatomico-physiologici minoris, Segmentum Primum; Seu Dissertatio Prima De oeconomia corporis animalis. Dorpati: excudit Johannes Brendeken, Acad. Typographus.

Bohn, Johannes 1686. Circulus anatomico-physiologicus seu oeconomia corporis animalis. Lipsiae, sumptibus Joh. Friedrich Gleditsch, Typis Christophori Fleischeri.

Bohn, Johannes 1697. Circulus anatomico-physiologicus seu oeconomia corporis animalis, seu Oeconomia corporis animalis, hoc est, cogitata, functionum animalium potissimarum formalitatem et causas concernantia. Lipsiae, Apud Thomam Fritsch.

Constitutiones 1997 = Lepajõe, Marju (toim). Constitutiones Academiae Dorpatensis (Academia Gustaviana) = Tartu Akadeemia (Academia Gustaviana) põhikiri . Tartu: Tartu Ülikooli Kirjastus.

Hein, Fridericus 1637. Oratio de medicina. Dorpati Livonorum: Lit. acad.

Hippocrates 1981 = Hippocrates with an English translation by W. H. S. Jones, II. The Loeb Classical Library. Cambridge, Massachusetts: Harvard University Press, London: William Heinemann LTD, lk 255-265.

Magirus, Joannes 1601. In physiologiam suam Peripateticam commentarius. Nebenius: Lichae.

Stregnensis, Johannes \& Andreas Arvidi 1647. Disputatio physica de plantis. Dorpati Livonorum: J. Vogelius.

Wallander, Segvardus Olai 1640. Oratio de homine. Dorpati Livonorum: Lit. Acad.

Wirdig, Sebastian \& Andreas Arvidi 1648. Disputatio medica de natura et constitutione medicinae. Dorpati Livonorum: J. Vogelius. 


\section{Kasutatud veebiallikad}

Ilias. I laul (https://www.perseus.tufts.edu/hopper/text?doc=Perseus\%3Atext\%3A1999 .01.0133\%3Abook\%3D1\%3Acard\%3D33 - 22. oktoober 2020).

Ovidius. Metamorfoosid. I raamat (http://www.thelatinlibrary.com/ovid/ovid.met1. shtml - 22. oktoober 2020).

Piibel (https://piibel.net/ - 22. oktoober 2020).

Plinius Vanem. Looduslugu, VIII rmt, 41 ptk. (https://www.perseus.tufts.edu/hopper/text ?doc=Perseus\%3Atext\%3A1999.02.0138\%3Abook\%3D8\%3Achapter\%3D41 - 22. oktoober 2020).

Vulgata = Latin Vulgate Bible (http://www.drbo.org/lvb/ - 22. oktoober 2020).

\section{Kirjandus}

Achner, Heike 2009. Ärzte in der Antike. Mainz: Verlag Philipp von Zabern.

Blackburn, Simon 2002. Oxfordi filosoofialeksikon. Tallinn: Vagabund.

Brockliss, Laurence \& Jones, Colin 1997. The Medical World of Early Modern France. Oxford: Clarendon Press.

Enenkel Karl A. E. \& Smith Paul J. (koost) 2007. Early Modern Zoology. The Construction of Animals in Science, Literature and the Visual Arts. Intersections 7. 2. kd. Leiden \& Boston: Brill.

Enenkel Karl A. E. \& Smith Paul J. (koost) 2014. Zoology in Early Modern Culture. Intersections of Science, Theology, Philology and Political and Religious Education, kd 32, Leiden \& Boston: Brill.

Franco, Nuno Henrique 2013. Animal Experiments in Biomedical Research: A Historical Perspective. Animals 3 (1), lk 238-273 (doi: 10.3390/ani3010238).

Garrison, Fielding H. 1960. An Introduction to the History of Medicine. Philadelphia \& London: W. B. Saunders Company.

Gerabek, Werner E. \& Haage, Bernhard D. \& Keil, Gundolf \& Wegner, Wolfgang (koost) 2007. Enzyklopädie Medizingeschichte. 1. kd. Berlin \& New York: Walter de Gruyter.

Hoffstadt, Christian \& Peschke, Franz \& Nagenborg, Michael \& Müller, Sabine (koost) 2012. Humana - Animalia. Mensch und Tier in Medizin, Philosophie und Kultur. Aspekte der Medizinphilosophie, kd 13. Bochum/Freiburg.

Kallinen, Maija 1995. Change and Stability. Natural Philosophy at the Academy of Turku (1640-1713). Studia Historica 51. Helsinki: Finnish Historical Society.

Kalling, Ken 2017. Meditsiini ajalugu. Tartu: Tartu Ülikooli peremeditsiini ja rahvatervishoiu instituut.

Korhonen, Tua \& Ruonakoski, Erika 2017. Human and Animal in Ancient Greece. Empathy and Encounter in Classical Literature. London, New York: I. B. Tauris. 
Kutschera, Ulrich 2011. From the scala naturae to the symbiogenetic and dynamic tree of life. Biology Direct 6 (33), lk. 1-25 (doi: 10.1186/1745-6150-6-33).

Kõivupuu, Marju 2017. Loomad eestlaste elus ja folklooris. Tallinn: Tänapäev.

Leven, Karl-Heinz (koost.) 2005. Antike Medizin. Ein Lexikon. München: C. H. Beck.

Muratori, Cecilia 2017. From Animal Bodies To Human Souls: (Pseudo-)Aristotelian Animals in Della Porta's Physiognomics. Early Science and Medicine 22 (1). Leiden, Boston: Brill, lk 1-23 (doi: 10.1163/15733823-00221p01).

Piirimäe, Helmut (koost) 1982. Tartu Ülikooli ajalugu I 1632-1798. Tallinn: Valgus.

Porter, Roy 1999. The greatest benefit to mankind. A medical history of humanity from antiquity to the present. Hammersmith, London: Fontana Press, An Imprint of Harper Collins Publishers.

Rauch, Georg von 1943. Die Universität Dorpat und das Eindringen der Frühen Aufklärung in Livland 1690-1710. Essen: Essener Verlagsanstalt.

Recke, Johann Friedrich von \& Napiersky, Karl Eduard 1831. Allgemeines Schriftstellerund Gelehrten-Lexikon der Provinzen Livland, Esthland und Kurland. 1. kd. Mitau: J. F. Steffenhagen u. Sohn.

Rein, Kaarina 2008. Andreas Arvidi disputatsioon De natura et constitutione medicinae arstiteadusliku mõtte arengu peegeldajana 17. sajandi Tartu ülikoolis. Mäetagused 39, lk 7-28 (doi: 10.7592/MT2008.39.rein).

Rein, Kaarina 2011. Arstiteadus rootsiaegses Tartu gümnaasiumis ja ülikoolis aastatel 1630-1656. Meditsiinialased disputatsioonid ja oratsioonid ning nende autorid. Tartu: Tartu Ülikooli Kirjastus (https://dspace.ut.ee/handle/10062/17146 - 22. oktoober 2020).

Rein, Kaarina 2013. Euroopalikust meditsiinist Tartus keskajast 17. sajandi keskpaigani. Opetatud Eesti Seltsi aastaraamat / Annales Litterarum Societatis Esthonicae, lk 33-56 (http://oes.ut.ee/wp-content/uploads/Rein1.pdf - 22. oktoober 2020).

Rein, Kaarina 2014. Tartu as the Eastern Outpost of European Medicine in the First Half of the 17th Century. Acta Baltica Historiae et Philosophiae Scientiarum 2 (1), lk 37-52 (doi: 10.11590/abhps.2014.1.03).

Rein, Kaarina 2017. Medizin und Theologie in Dorpat (Tartu) im 17. Jahrhundert. Assel, Heinrich \& Steiger, Johann Anselm \& Walter, Axel E. (koost). Reformatio Baltica. Kulturwirkungen der Reformation in den Metropolen des Ostseeraums. Berlin, Boston: De Gruyter, lk 699-709 (doi: 10.1515/9783110573558-038).

Rein, Kaarina 2019. Medical Orations in the 17th Century Tartu. Berzina, Gita \& Gorneva, Ilona (koost). Anitiquitas Viva 5. Studia Classica. Riga: University of Latvia Press, 2019, lk 151-161 (doi: 10.22364/av5.13).

Rein, Kaarina 2020. Rootsiaegse Tartu ülikooli disputatsioon "Taimedest”. Vikerkaar 7-8, lk 24-26.

Sõukand, Renata 2006. Koera keele otsas rohi, kassi keele otsas tõbi. Mäetagused 31, lk 87-105 (doi: 10.7592/MT2005.31.renata).

Tering, Arvo 1996. René Descartes’i ideede jõudmisest Eesti-ja Liivimaale XVII sajandil ja XVIII sajandi algul. Keel ja Kirjandus 3, lk 179-188. 
Valdes, Albert \& Veski, Johann Voldemar 1982-1983. Ladina-eesti-vene meditsiinisõnaraamat kd 1-2. Tallinn: Valgus.

White, Cynthia 2017. Potiones ad sanandum: Text as Remedy in a Medieval Latin Bestiary. Classen, Albrecht (koost). Bodily and Spiritual Hygiene in Medieval and Early Modern Literature. Explorations of Textual Presentations of Filth and Water. Berlin \& Boston: De Gruyter, lk 221-274 (doi: 10.1515/9783110523799-008).

Wright, Thomas 2013. William Harvey. A Life in Circulation. New York, Oxford: Oxford University Press.

\title{
Summary
}

\section{Animals in the medical works of the Swedish-period University of Tartu}

\author{
Kaarina Rein \\ Research Fellow \\ Research Centre of the University of Tartu Library \\ kaarina.rein@ut.ee
}

Keywords: early modern disputations, early modern medicine, natural sciences in early modern era, orations and dissertations, the Swedish-period University of Tartu

At the Swedish-period University of Tartu there were four medical works which described or mentioned animals in some connection. Animals were often used as metaphors in these works in order to draw parallels with humans. In this connection animals were rather considered to be inferior to humans as it was typical to the early modern period.

In the medical works of the 17th century University of Tartu veterinary medicine is mentioned and also the use of animals as a source of remedies or even animals as their own doctors, teaching the humans how to heal certain diseases. There are hints to animals in scientific experiments. In the medical work Dissertatio prima de oeconomia corporis animalis, originating from 1698, the development of early modern physiology can be observed.

There is a clear difference between the works which were compiled in the first half of the 17 th century and the dissertation written at the end of the same century. The works that were written earlier were mostly based on ancient authors, whereas the dissertation from the end of the 17th century delivers empirical knowledge.

Thus animals had their impact on the medicine of the 17th century University of Tartu as well as on the way of talking and writing about medicine.

Kaarina Rein on Tartu Ülikoolis õppinud klassikalist filoloogiat ning kaitsnud 2011. aastal TÜ usuteaduskonnas väitekirja rootsiaegse Tartu ülikooli meditsiinitöödest. Tema uurimishuvid on olnud klassikaliste keelte õpetamine, 
kreeka ja ladina pärisnimed eesti keeles, varauusaegsed disputatsioonid ning antiikkeelte ja -kirjanduse retseptsioon Eestis. Tartu Ülikoolis on ta töötanud õppejõu ja teadurina.

Kaarina Rein has studied classical philology at the University of Tartu and defended her doctoral thesis on the medical disputations and orations of the Swedish University of Tartu at the Faculty of Theology of the University of Tartu in 2011. Her research interests have been teaching classical languages, Greek and Latin proper names in Estonian, early modern disputations and the reception of ancient languages and literature in Estonia. At the University of Tartu she has held the positions of a lecturer and a researcher.

kaarina.rein@ut.ee 